\title{
Calpain Activation Contributes to Dendritic Remodeling after Brief Excitotoxic Injury In Vitro
}

\author{
Brian T. Faddis, M. Josh Hasbani, and Mark P. Goldberg \\ Departments of Neurology and Anatomy and Neurobiology, Center for the Study of Nervous System Injury, Washington \\ University School of Medicine, St. Louis, Missouri 63110
}

\begin{abstract}
The calcium-dependent protease calpain may contribute to neuronal death in acute neurological insults and may be activated very early in the neuronal injury cascade. We assessed the role of calpain in a model of rapid, reversible dendritic injury in murine cortical cultures. Brief sublethal NMDA exposure (10-30 $\mu \mathrm{m}$ for $10 \mathrm{~min}$ ) resulted in focal swellings, or varicosities, along the length of neuronal dendrites as visualized with the lipophilic membrane tracer Dil or with immunostaining using antibodies to the somatodendritic protein MAP2. These varicosities appeared within minutes of NMDA exposure and recovered spontaneously within $2 \mathrm{hr}$ after NMDA removal. Addition of the calpain inhibitors MDL28,170, calpain inhibitors I and II, and leupeptin (all 1-100 $\mu \mathrm{M}$ ) had little effect on the development of NMDA-induced dendrite injury. However, the resolution of varicosities was substantially delayed by addition of calpain
\end{abstract}

inhibitors after sublethal excitotoxic exposure. Using Western blots and immunocytochemistry, we observed reactivity for a calpain-specific spectrin proteolytic fragment during the period of recovery from dendritic swelling, but not during its formation. Spectrin breakdown product immunoreactivity could be blocked by the calpain inhibitor MDL28,170 and appeared in neuronal cell bodies and neurites in a time course that paralleled dendritic recovery. These observations suggest that calcium-dependent proteolysis contributes to recovery of dendritic structure after NMDA exposure. Calpain activation is not necessarily detrimental and may play a role in dendritic remodeling after neuronal injury.

Key words: excitotoxicity; calpain; neuronal injury; cell culture; cytoskeleton; glutamate; spectrin
The calcium-activated cysteine proteases, or calpains, have been implicated as a major component in a cascade of events leading to neuronal death in the setting of excitotoxic, hypoxic, and traumatic insults (Wang and Yuen, 1994; Bartus et al., 1995). Calpainmediated proteolysis is selective for a subset of cellular proteins that include cytoskeletal and membrane proteins, kinases, phosphatases, and transcription factors (Goll et al., 1992; Saido et al., 1994). Although calpain isoforms are present in all vertebrate cells, the role of calpain under physiological conditions remains poorly understood. When intracellular calcium levels are markedly elevated under pathological conditions, however, the resulting calpain activation can be a destructive force within the cell.

There is substantial evidence that calpain-mediated proteolysis occurs in many settings of acute neuronal injury (Wang and Yuen, 1994). Pharmacological inhibition of calpain is neuroprotective in many, though not all, models. The effects of calpain inhibitors have been variable in in vitro systems and are influenced, perhaps, by cell type and mode of injury (Di Stasi et al., 1991; Manev et al., 1991; Caner et al., 1993; Rami and Krieglstein, 1993; Brorson et al., 1995; Chard et al., 1995; Wang et al., 1996). Calpain inhibitors

Received Aug. 16, 1996; revised Nov. 7, 1996; accepted Nov. 8, 1996.

This work was supported by National Institutes of Health Grants NS01543 and NS32140 (M.P.G.). This work was done during the tenure of a grant-in-aid award (M.P.G.) from the American Heart Association and William Randolph Hearst Foundation. We thank Jeannie David, Jennifer Freeman, and Sandy Althomsons for expert technical assistance; Laura Dugan for helpful discussion; and James Meschia, David Gutmann, Andreas Kampfl, and Ron Hayes for assistance with immunoblotting methods. R. Siman generously provided the monoclonal antibody Ab38.

Correspondence should be addressed to Dr. Mark P. Goldberg, Department of Neurology, Campus Box 8111, Washington University School of Medicine, 660 South Euclid Avenue, St. Louis, MO 63110.

Dr. Faddis's present address: Department of Research, Central Institute for the Deaf, St. Louis, MO 63110.

Copyright (C) 1997 Society for Neuroscience $\quad 0270-6474 / 97 / 170951-09 \$ 05.00 / 0$ reduce proteolysis and cell death in several in vivo models of cerebral ischemia and brain trauma (Lee et al., 1991; Bartus et al., 1994; Saatman et al., 1996). Accordingly, substantial interest has been generated in assessing the therapeutic potential of calpain inhibitors in a variety of neurological disorders (Siman, 1992; Wang and Yuen, 1994; Bartus, 1995; Linnik, 1996).

We examined the role of calpain in dendritic injury after glutamate receptor activation. A common manifestation of many forms of neuronal injury is the formation of focal swellings or varicosities along the length of the dendritic arbor. This pattern of dendritic injury, illustrated by Ramón y Cajal a century ago (Ramón y Cajal, 1909, 1995), has been observed in neuronal injury models both in vivo (Olney, 1971; Hsu and Buzsaki, 1993; Kwei et al., 1993; Hori and Carpenter, 1994; Matesic and Lin, 1994) and in vitro (Stewart et al., 1991; Bateman and Goldberg, 1992; Bindokas and Miller, 1995; Emery and Lucas, 1995). In cultured mouse cortical neurons, NMDA receptor-dependent dendritic varicosity formation occurs during exposure to oxygen and glucose deprivation and can be reproduced within minutes of exposure to glutamate or NMDA (Bateman and Goldberg, 1992; Park et al., 1996). Interestingly, dendritic varicosities form even after brief sublethal excitotoxic exposure, and they resolve spontaneously within 1-2 hr (Park et al., 1996). Because increased intracellular calcium is a critical step of the excitotoxic injury cascade, we considered the hypothesis that calpain-mediated cytoskeletal proteolysis might be a central event leading to dendritic varicosity formation. Here we present observations that suggest calpain activation does not have a major role in formation of rapid dendritic injury. In contrast, calpain seems to be critical for spontaneous recovery after sublethal neuronal injury. 
Preliminary reports have appeared in abstract form (Faddis and Goldberg, 1995; Meschia et al., 1995).

\section{MATERIALS AND METHODS}

Mouse cortical cell culture. Mouse neocortical neurons from gestational day 15 embryos were dissociated and plated on confluent astrocyte cultures at 2 weeks in vitro as described previously (Rose et al., 1993). Culture substrates included glass coverslips glued to the bottom of cutout $35 \mathrm{~mm}$ culture dishes (MatTek, Ashland, MA), which were coated with poly-D-lysine (5\%, room temperature for $2 \mathrm{hr})$ and laminin $(0.01 \mathrm{mg} / \mathrm{ml}$, room temperature for $2 \mathrm{hr}$ ). Tissue culture-treated polystyrene 24-well plates (Falcon Primaria, Lincoln Park, NJ) were used also. Cells were plated at a density of 2-3 neocortex hemispheres per $10 \mathrm{cc}$ plating media, which contained 5\% horse serum, 5\% fetal bovine serum, $200 \mathrm{~mm}$ glutamine, $12.9 \mathrm{~mm} \mathrm{NaHCO}$, and $10 \mathrm{~mm}$ D-glucose in MEM. Cultures were maintained at $37^{\circ} \mathrm{C}$ with $5 \% \mathrm{CO}_{2}$. After $7 \mathrm{~d}$ in vitro (DIV), proliferation of non-neuronal cells was halted by treatment with $10 \mu \mathrm{M}$ cytosine arabinoside for 1-3 d. Experimental procedures were conducted on cultures at 14-17 DIV, when the density of synaptic contacts was sufficient to produce an excitotoxic response to NMDA exposure.

$N M D A$ exposure. All experimental pretreatments and treatments were conducted in a HEPES- and bicarbonate-buffered balanced salt solution (HBBSS), with the following components (in $\mathrm{mm}$ ): $\mathrm{NaCl}(116), \mathrm{KCl}$ (0.40), $\mathrm{MgSO}_{4} 7 \mathrm{H}_{2} \mathrm{O}(0.80), \mathrm{NaH}_{2} \mathrm{PO}_{4}$ (1.01), $\mathrm{NaHCO}_{3}$ (25), HEPES (12), D-glucose (5.5), $\mathrm{CaCl}_{2}(1.8)$, and phenol red, $\mathrm{pH}$ 7.4. After thorough medium exchange to remove serum-containing culture media, cells were exposed to wash conditions or to 5-50 $\mu \mathrm{M}$ NMDA (dissolved in HBBSS) for $10 \mathrm{~min}$ at room temperature. In some experiments, cultures were transferred to DMEM and returned to the $37^{\circ} \mathrm{C}$ culture incubator for 1-24 hr. Cultures were additionally exposed to the calpain inhibitors leupeptin (Sigma, St. Louis, MO), calpain inhibitors I and II (Sigma), or MDL28,170 (CbzValPheH; generously provided by Hoechst Marion Roussel, Frankfort, Germany) either 2 hr before NMDA exposure (pretreatment) or immediately after NMDA exposure (post-treatment). All inhibitor stock solutions $(10 \mathrm{~mm})$ were prepared in $100 \%$ ethanol, except for MDL28,170 (100 mM), which was prepared in DMSO. The final concentration of each vehicle was $\leq 1.0 \%$ ethanol or $\leq 0.1 \%$ DMSO. The presence of vehicle alone had no effect on dendritic varicosity formation or recovery.

Experiments were terminated by fixing the cultures in $4 \%$ paraformaldehyde and $0.025 \%$ glutaraldehyde in PBS for $30 \mathrm{~min}$ or by harvesting the cell proteins as described below. All experiments included sister cultures, exposed only to wash conditions, and cultures exposed to NMDA but with no additional drug. All experiments were repeated at least three times with cultures from different platings.

Assessment of neuronal injury and cell morphology. After each experiment, cultures were examined with phase-contrast microscopy (100$400 \times)$. Cell viability was assessed additionally by measurement of the cytosolic enzyme lactate dehydrogenase $(\mathrm{LDH})$ released by damaged cells into the bathing medium (Koh and Choi, 1987). Dendritic morphology after culture fixation was assessed via two independent techniques (Park et al., 1996). To obtain a quantitative assessment of varicosity formation, we labeled cultures with the carbanocyanine membrane tracer $\operatorname{DiI}\left(\mathrm{C}_{18}\right)_{3}$ ("DiI;" Molecular Probes, Eugene, OR) (Honig and Hume, 1986) as follows. A DiI stock solution of $0.5 \mathrm{mg} / \mathrm{ml}$ was prepared in ethanol and stored at $-20^{\circ} \mathrm{C}$. Immediately before use, the stock was diluted $100 \times$ in PBS, and this suspension was vortexed continuously for 2 min. Fixed cells were washed briefly with PBS; then this was removed and cells were incubated in the DiI suspension for $75 \mathrm{~min}$ at room temperature. The DiI incubation was terminated by washing cultures back into PBS. This procedure resulted in random labeling of a small proportion of the cultured neurons; because each neuron was labeled throughout the dendritic arbor, the method allowed reliable counts of the proportion of cells displaying dendritic varicosities. MAP2 immunofluorescence was used to demonstrate varicosity formation and recovery in all dendrites in the culture (see Immunocytochemistry, below).

Quantification and statistical analysis. DiI-labeled cultures were examined at $400 \times$ under epifluorescence illumination. For each experimental condition, 50 consecutive neurons in two cultures were scored for the presence or absence of dendritic beading. The resulting values were averaged for three independent experiments. A one-way ANOVA, followed by Tukey multiple comparisons, was used to demonstrate significant effects of calpain inhibition on dendritic bead formation and recovery.

Immunocytochemistry. After experimental treatment, cells were fixed at room temperature in $4 \%$ paraformaldehyde and $0.025 \%$ glutaraldehyde in PBS. Cultures were washed in PBS, incubated in $0.25 \%$ Triton X-100 at room temperature for $10 \mathrm{~min}$, and blocked in $10 \%$ normal goat serum for $60 \mathrm{~min}$. A monoclonal antibody to MAP2 (AP-20, Boehringer Mannheim, Indianapolis, IN) was used at a dilution of 1:400-1:800 for $2 \mathrm{hr}$ at room temperature or overnight at $4^{\circ} \mathrm{C}$. A mouse monoclonal antibody to calpain I (MAB3082, Chemicon, Temecula, CA) and a rabbit polyclonal antibody to calpain II (AB1625, Chemicon) were used at a dilution of 1:100 and 1:50, respectively, overnight at $4^{\circ} \mathrm{C}$. A calpain-specific spectrin breakdown product was visualized by monoclonal antibody Ab38 (generously provided by R. Siman, Cephalon, West Chester, PA) at 1:5000 at $4^{\circ} \mathrm{C}$ overnight. The spectrin proteolytic fragment recognized by such antibodies is formed by brain calpain, but not by several other proteases, including cathepsins (Saido et al., 1993; Roberts-Lewis et al., 1994). Therefore, Ab38 reactivity represents a useful, selective marker for active calpain during neuronal injury. Primary antibodies were washed off via several changes of PBS and replaced with Cy3-conjugated goat antimouse or anti-rabbit IgG (Jackson ImmunoResearch Labs, West Grove, PA) at 1:50-1:100 for 30-60 min.

Cultures were examined with an epifluorescence microscope (200$600 \times$; Nikon Diaphot) with $75 \mathrm{~W}$ xenon illumination and standard rhodamine filter cubes. Video images were acquired with a siliconintensified target (SIT) camera (Hamamatsu), and captured with a PCbased image analysis system (MetaMorph, Universal Imaging, West Chester, PA).

Western blot analysis. To assess the activation of calpain, we probed Western blots with Ab38, the antibody to calpain-specific spectrin proteolytic fragment. After experimental treatment, cultures were rinsed twice with PBS and scraped from their substrate in chilled $\left(4^{\circ} \mathrm{C}\right)$ lysate buffer containing $50 \mathrm{~mm}$ Tris- $\mathrm{HCl}, 150 \mathrm{~mm} \mathrm{NaCl}, 0.5 \%$ SDS, $0.02 \%$ sodium azide, $2.0 \mathrm{~mm}$ EGTA, $1.0 \mathrm{~mm}$ EDTA, $1 \% \mathrm{NP}-40,100 \mu \mathrm{g} / \mathrm{ml}$ PMSF, $1.0 \mu \mathrm{g} / \mathrm{ml}$ aprotinin, and $0.1 \mathrm{~mm}$ leupeptin. Samples were centrifuged for $10 \mathrm{~min}$ at $13,000 \mathrm{rpm}$ in the cold and the supernates assayed and corrected for total protein content. Protein samples $(10 \mu \mathrm{g})$ were run on precast $7.5 \%$ minigels (Bio-Rad, Hercules, CA) along with prestained markers and transferred to polyvinylidene fluoride (PVDF) membranes. Western blots were probed with $\mathrm{Ab} 38$ at 1:2000 in 5\% nonfat milk powder overnight at $4^{\circ} \mathrm{C}$. Blots were rinsed in TBS with $0.1 \%$ Tween-20 and incubated in HRP-conjugated goat anti-rabbit IgG (1:3000, BioRad). Labeled proteins were visualized with chemiluminescent techniques (ECL Reagents, Amersham, Buckinghamshire, England).

\section{RESULTS}

\section{NMDA-induced dendritic injury and recovery}

In fixed cortical cultures, immunofluorescence using antibodies to the somatodendritic microtubule-associated protein MAP2 revealed neurons with round somata and an intricately branched dendritic arbor with smooth dendrites (Fig. 1 $A$ ). Fluorescent labeling using a suspension of the membrane tracer $\operatorname{DiI}\left(\mathrm{C}_{18}\right)_{3}$ in living or fixed cultures demonstrated a similar morphology, except that dendritic spines were readily visualized along the contour of the otherwise smooth dendrites, and axons could be observed arising from the soma or proximal dendrite. When cultures were exposed to $30 \mu \mathrm{M}$ NMDA for $10 \mathrm{~min}$ and fixed immediately, neurons showed the appearance of focal swellings or beads along the length of the dendrite (Fig. $1 B$ ). Distal portions of the dendrite more frequently exhibited varicosities than proximal portions, and varicosities occurred with a regular periodicity. Axons did not show focal swelling. Although MAP2 immunofluorescence suggested the appearance of discrete fragmented dendrites, DiI labeling indicated that dendritic membranes remained contiguous. NMDA exposure was associated with a change in distribution of MAP2 immunoreactivity, which was decreased in distal dendrites and increased in neuronal somata and proximal dendrites.

NMDA-induced varicosity formation of mouse cortical neurons occurred in a concentration-dependent manner (Fig. 3). A small background level of varicosity formation was evident even in control cultures exposed only to wash conditions. A $10 \mathrm{~min}$ exposure to NMDA at concentrations of 5 and $10 \mu \mathrm{M}$ caused a 

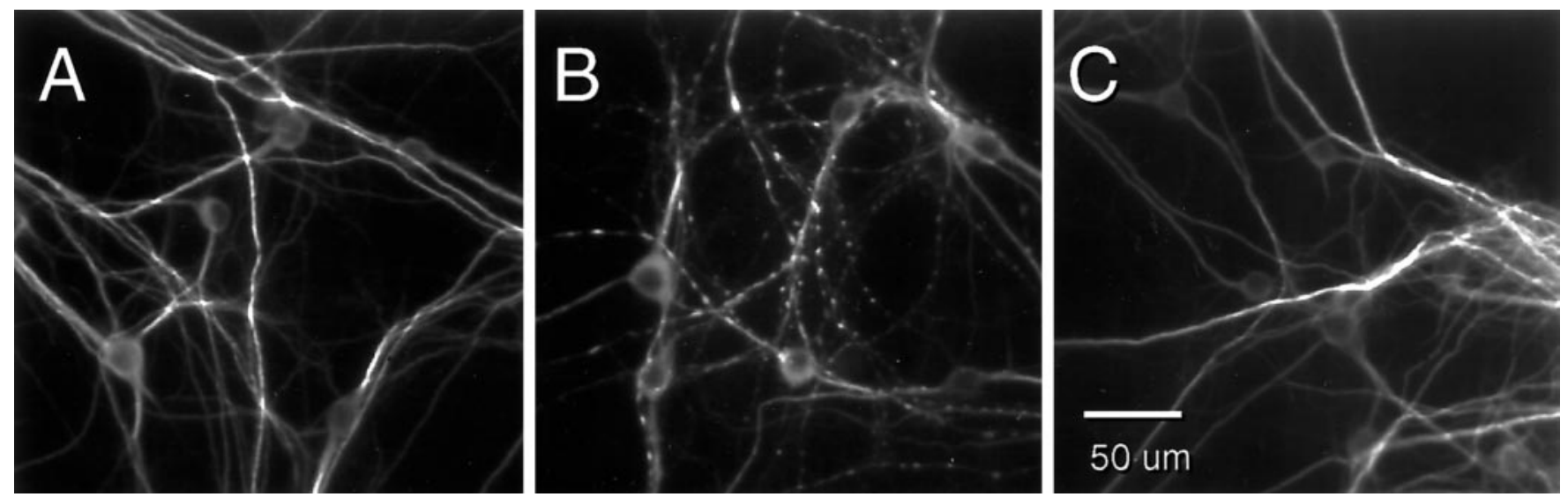

Figure 1. NMDA-induced varicosity formation and recovery in mouse cortical neurons. MAP2 immunofluorescence is shown for sister cortical cultures demonstrating the effects of the following treatments: $A$, wash control; $B$, exposure to $30 \mu \mathrm{M}$ NMDA for 10 min, followed by immediate fixation; and $C$, 10 min exposure to NMDA, followed by recovery in normal culture medium for 90 min. NMDA exposure results in widespread appearance of dendritic varicosities, which resolve over the subsequent 30-120 min.

minimal increase in the amount of varicosity formation, whereas 30 and $50 \mu \mathrm{M}$ NMDA resulted in near-maximal varicosity formation. NMDA-induced dendritic injury was blocked by addition of the selective NMDA receptor antagonist, $10 \mu \mathrm{M}$ MK-801.

Dendritic varicosity formation was reversible if NMDA was removed after brief (10 min) exposure (Fig. 1C). NMDA exposure at these concentrations was not lethal: phase-contrast microscopy and assay for LDH efflux performed $24 \mathrm{hr}$ after NMDA exposure showed no evidence of increased toxicity, as compared with wash control sister cultures. Cultured cortical neurons exposed to 30 $\mu \mathrm{M}$ NMDA for $10 \mathrm{~min}$ and washed back into normal balanced salt solution showed significant time-dependent recovery of dendritic shape (Fig. 5). The most significant portion of recovery occurred during the first 30-60 min, when the percentage of neurons with varicosities decreased from 90 to $20 \%$. Recovery progressed almost to wash levels by the end of a $120 \mathrm{~min}$ postexposure period.

\section{Effects of calpain inhibitors on dendritic injury and recovery}

Calpain is expressed ubiquitously in central neurons and glia in vivo (Ivy et al., 1988; Perlmutter et al., 1988), but its distribution has not been characterized in murine cortical neuronal cultures. Immunofluorescence using antibodies to calpain I ( $\mu$-calpain) revealed diffuse labeling of neuronal somata, excluding nuclei, with some reactivity in neurites (Fig. $2 A, B$ ). Antibodies to calpain II (m-calpain) also demonstrated fluorescence in neuronal cytoplasm and emphasized the presence of this isoform in neurites (Fig. 2C,D).

We used pharmacological inhibition of calpain to examine the hypothesis that NMDA-induced varicosity formation was mediated by calcium-dependent proteolysis. Dendritic injury was not reduced when sister cultures were treated during NMDA exposure with calpain inhibitors, including leupeptin and calpain inhibitors I and II (all 1-100 $\mu \mathrm{M}$; data not shown). A 2 hr pretreatment and cotreatment with the cell-permeant calpain inhibitor MDL28,170 (Mehdi, 1993) (1-100 $\mu \mathrm{M})$ also had little effect on dendritic varicosity formation at most concentrations of NMDA (Fig. 3). MDL28,170 pre/cotreatment did result in a small, but statistically significant, reduction in varicosity formation in the 20 $\mu \mathrm{M}$ NMDA group (Fig. 3).

Surprisingly, addition of MDL28,170 during the postexposure period significantly reduced the rate of recovery from NMDAinduced varicosity formation. This effect was especially evident in cultures immunostained with antibodies to MAP2, because all dendrites were visualized (Fig. 4). In quantitative studies, the percentage of DiI-labeled neurons with varicosities in the MDL28,170 post-treatment group was approximately twice that of the non-MDL28,170 group at 30 and 120 min postexposure (Fig. 5). Additional studies showed that other inhibitors of calpain, including leupeptin and calpain inhibitors I and II (1-100 $\mu \mathrm{M})$, also attenuated recovery from NMDA-induced varicosity forma-
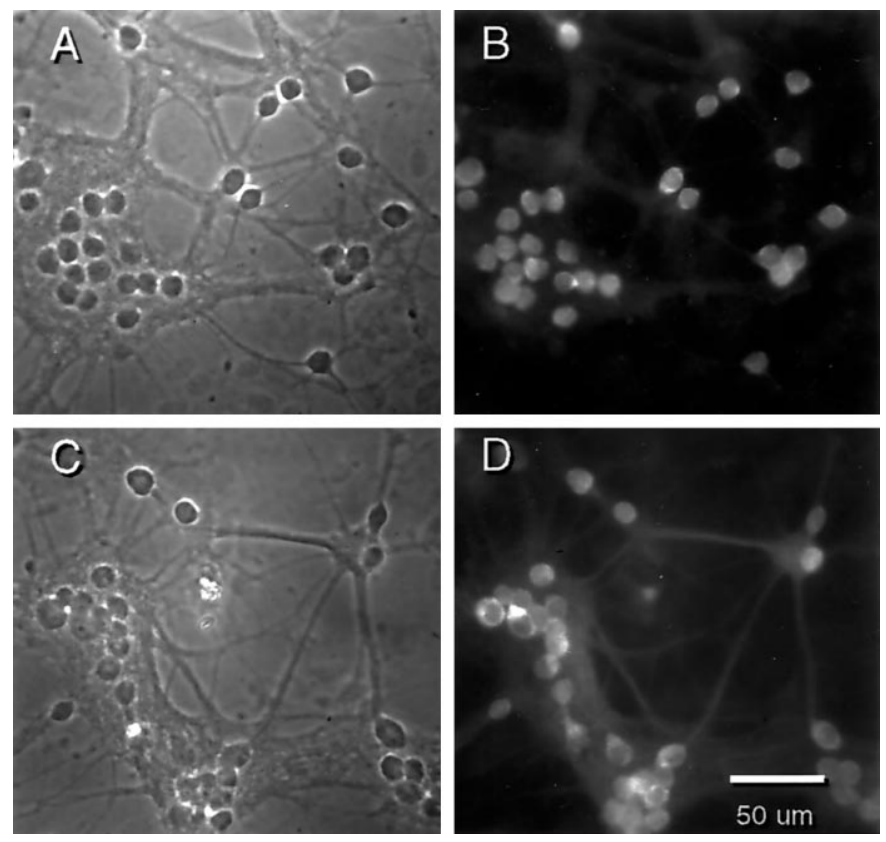

Figure 2. Calpain I and II immunoreactivity in cortical cultures. The distribution of calpain I $(A, B)$ and II $(C, D)$ was assessed by using antibodies specific for these two isoforms. Videomicrographs show phasecontrast $(A, C)$ and fluorescence $(B, D)$ images of the same fields in sister cultures. Immunofluorescence was detected in both neuronal somata and processes, although the calpain II fluorescence $(D)$ was much weaker than that for calpain I $(B)$. Camera exposure settings were not the same for these two images. Scale bar, $50 \mu \mathrm{m}$. 


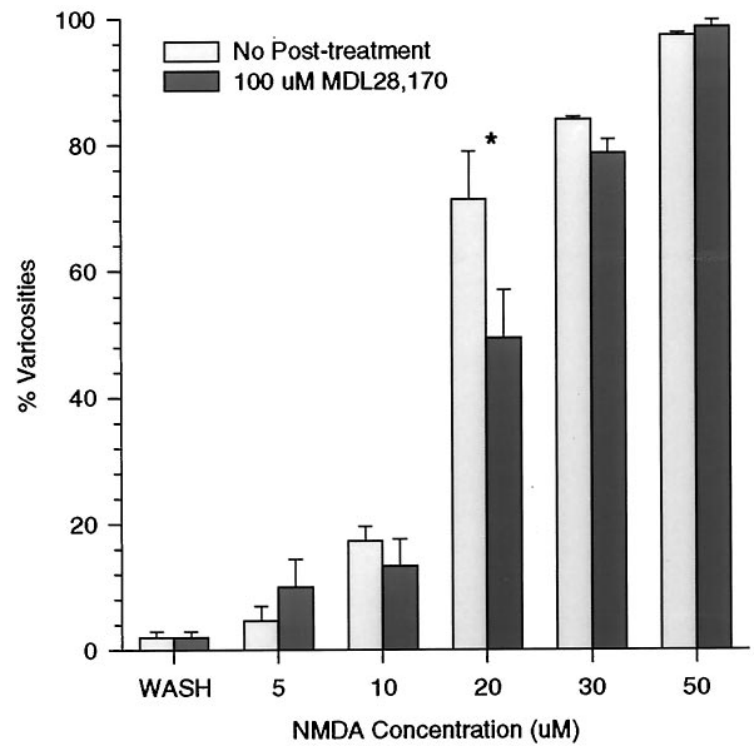

Figure 3. Effect of calpain inhibition on NMDA-induced varicosity formation. The histogram shows the concentration-dependent increase in the percentage of cells containing varicosities after a 10 min NMDA exposure. Pre- and cotreatment with the calpain inhibitor MDL 28,170 (100 $\mu \mathrm{M})$ attenuated varicosity formation produced by $20 \mu \mathrm{M}$ NMDA exposure, but not by other concentrations. Values represent the means \pm SE of counts from three independent experiments (50 observations per condition in each experiment). ${ }^{*} p<0.005$ by one-way ANOVA.

tion. The effect of the tested calpain inhibitors was concentrationdependent between 1 and $100 \mu \mathrm{M}$ (Fig. 6). Some varicosity recovery remained attenuated even $48 \mathrm{hr}(10 \mu \mathrm{M}$ MDL28,170) after NMDA exposure; however, the varicosities that persisted were small and usually limited to the most distal portions of the dendritic arbor.

Although addition of calpain inhibitors delayed recovery of dendritic shape, they did not increase the amount of neuronal death even when incubated for 24-48 hr after NMDA exposure. There was no evidence that delayed recovery of dendritic shape reflected direct neurotoxicity of the calpain inhibitors. Two hour exposure to MDL28,170 alone did not cause varicosity formation or other morphological change in control sister cultures over the course of these experiments and did not produce neuronal death by the next day. Prolonged exposure to high concentrations (100 $\mu \mathrm{M}$ for 24-48 hr) of MDL28,170 caused a small number of varicosities and slightly increased neuronal death $(<10 \%$; data not shown).

\section{Spectrin proteolysis during NMDA-induced varicosity formation and recovery}

Because pharmacological inhibition of calpain was effective in blocking dendritic recovery, but not initial dendritic injury, we sought specific evidence for calpain activity during and after NMDA exposure. Siman and colleagues recently have developed antibodies (Ab38 and Ab39) that recognize spectrin fragments specific for calpain-mediated proteolysis (Roberts-Lewis et al., 1994). Immunocytochemistry with Ab38 showed no increase over background signal with 10 min of NMDA exposure (Fig. 7A,B). Calpain-mediated spectrin proteolysis became evident in neuronal cell bodies and neurites during the subsequent 90 min recovery period (Fig. $7 D-F)$. Western blot analysis with Ab38 revealed the appearance of a $\sim 150 \mathrm{kDa}$ band, consistent with calpain-
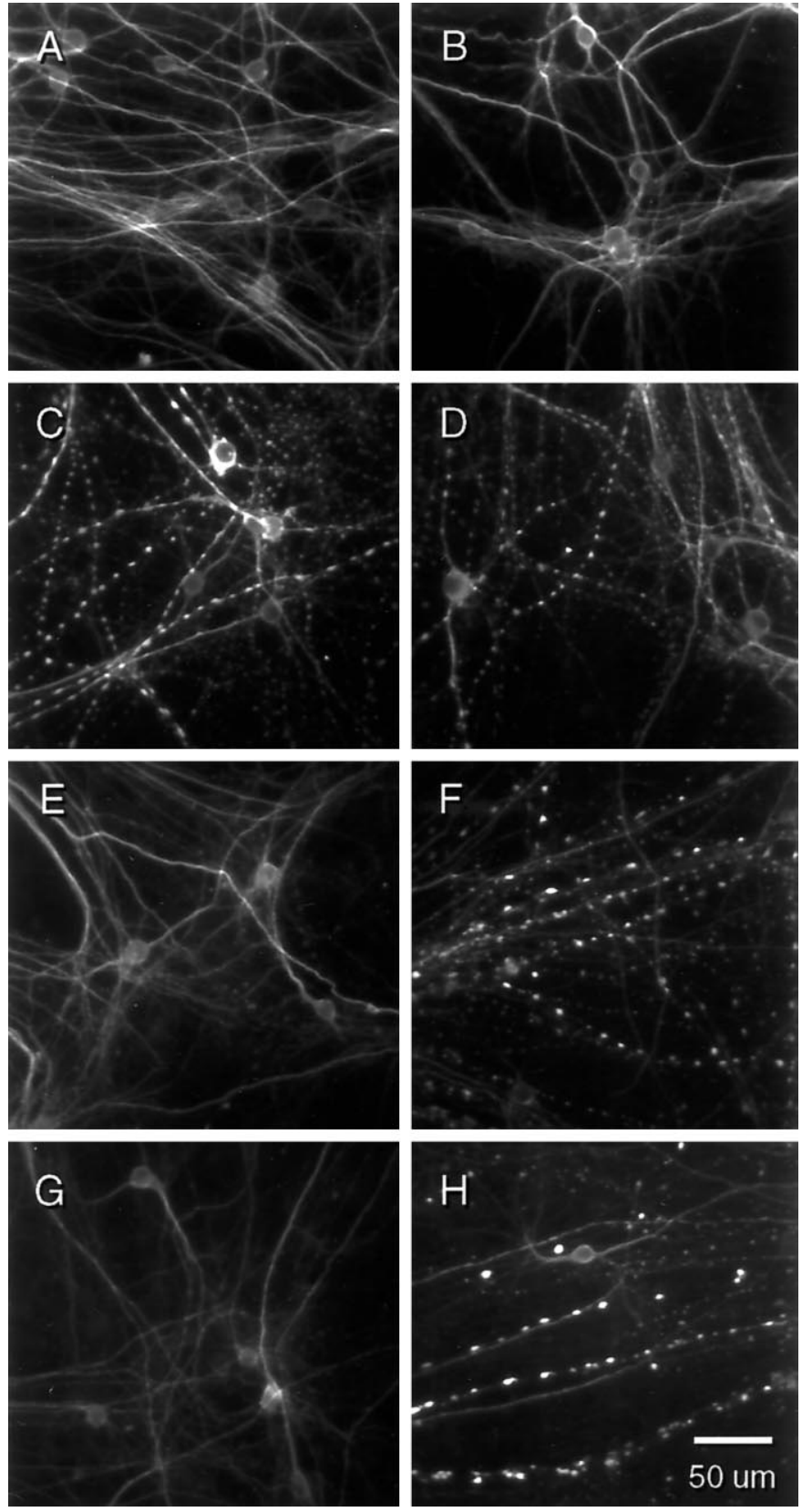

Figure 4. Recovery of NMDA-induced varicosities in the presence or absence of calpain inhibitor. Sister cultures were exposed to wash conditions $(A, B)$ or to $30 \mu \mathrm{M}$ NMDA $(C-H)$ for $10 \mathrm{~min}$. Cultures were fixed immediately $(C, D)$ or allowed to recover for $2(E, F)$ or $8(G, H) \mathrm{hr}$ in the absence (left) or presence (right) of the calpain inhibitor MDL28,170 (100 $\mu \mathrm{M})$. Immunofluorescence using antibodies against MAP2 demonstrates widespread dendritic beading after NMDA exposure, followed by spontaneous recovery over several hours. Addition of MDL28,170 after NMDA exposure substantially delayed recovery of dendritic shape. Scale bar, $50 \mu \mathrm{m}$.

specific spectrin breakdown product, between 30 and 90 min after 10 min NMDA exposure (Fig. 7G). This was not present in control cultures or in cultures harvested immediately after NMDA exposure (Fig. 7G). Post-treatment with $100 \mu \mathrm{M}$ MDL28,170 blocked appearance of the spectrin breakdown product demonstrated by Western blots (Fig. 7G) and immunocytochemistry (data not shown). The delayed time course of calpain 


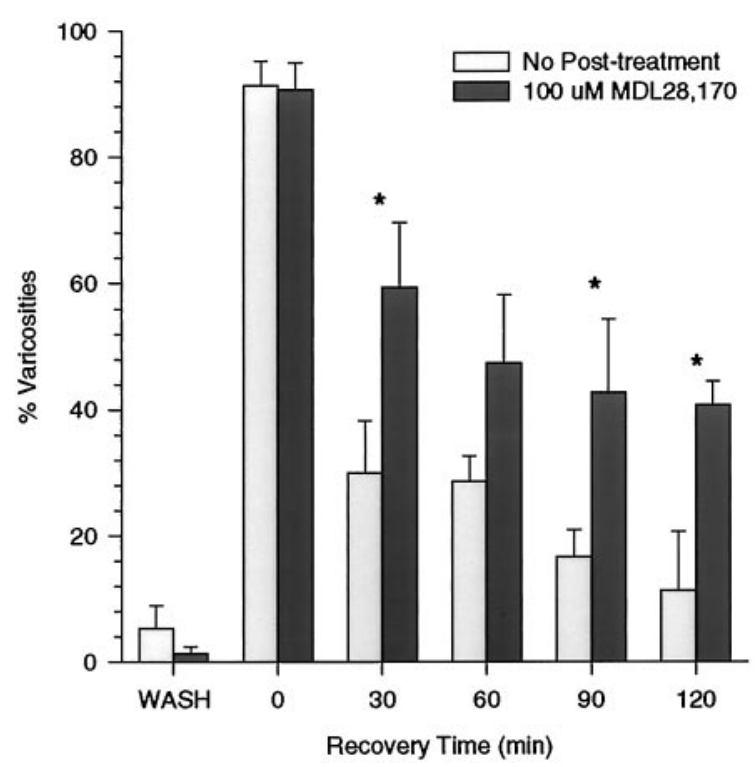

Figure 5. Calpain inhibition attenuates recovery of varicosity formation. The histogram shows the time course of varicosity recovery after $10 \mathrm{~min}$ of exposure to $30 \mu \mathrm{M}$ NMDA. Values represent the means \pm SE of counts from three independent experiments (50 observations per condition in each experiment). Post-treatment with $100 \mu \mathrm{M}$ MDL28,170 (dark bars) significantly attenuated recovery. ${ }^{*} p<0.05$ by one-way ANOVA.

activation observed in these studies suggested that protein synthesis might be required for reversal of dendritic varicosities; however, pretreatment with the protein synthesis inhibitor cycloheximide did not delay dendritic recovery (our unpublished results).

\section{DISCUSSION}

\section{Role of calpain in dendritic injury and recovery}

Acute swelling of the neuronal soma and dendrites is a pathological hallmark of excessive glutamate receptor activation, or excitotoxicity (Olney, 1971). This process can be examined directly in neuronal cell cultures, with visualization of dendrites by DiI labeling or MAP2 immunofluorescence. In cultured cortical neurons, NMDA receptor activation produces rapid focal swelling, or varicosities, along the length of the dendritic arbor. These alterations in dendritic shape do not indicate lethal or irreversible neuronal damage. Although prolonged NMDA exposure is neurotoxic, brief sublethal exposure results in extensive dendritic beading that resolves spontaneously over $2 \mathrm{hr}$ after agonist removal (Fig. 1; Park et al., 1996).

Intracellular calcium concentrations in neurons may be markedly elevated during intense glutamate receptor stimulation (MacDermott et al., 1986; Rajdev and Reynolds, 1993; Petrozzino et al., 1995; Hyrc et al., 1996). One consequence is activation of calcium-dependent protease, or calpain. Calpain is involved in cell death and in the formation of membrane blebs of several cell types, including hepatic and renal cells (Elliget et al., 1994; Miyoshi et al., 1996). Considering the wide distribution of calpain in the CNS, its activation by elevated intracellular calcium, and its ability to degrade cytoskeletal proteins, we felt that calpain activation in neurons might contribute to observed excitotoxic changes in dendritic structure. However, our results suggest that calpain activation does not play a significant role in formation of dendritic varicosities. Surprisingly, calpain activation seems to be required for restoration of dendritic structure.

Our study has two major observations. First, application of calpain inhibitors failed to alter dendritic swelling substantially during NMDA receptor activation. Some calpain inhibitors, such as leupeptin, are known to have relatively low potency and poor cell permeability, and it is possible that these agents did not reach sufficient intracellular concentrations. However, other inhibitors, including MDL28,170, have considerably greater cell permeability (Mehdi, 1991). Under our loading conditions, calpain inhibitors including MDL28,170 effectively blocked NMDA-induced proteolysis of calpain substrates, including MAP2 (Meschia et al., 1995) and spectrin (Fig. 7G). Therefore, the cell permeability and concentrations of these agents were sufficient to produce effective inhibition of calpain. In addition, during the $10 \mathrm{~min}$ period of dendritic varicosity formation, we did not observe a significant increase in immunoreactivity for the spectrin proteolytic fragment recognized by antibody Ab38. Because MDL28,170 did produce a small but statistically significant reduction of varicosity formation after application of $20 \mu \mathrm{M}$ NMDA (Fig. 4), we cannot exclude a small contribution of calpain activation in this process. However, it seems likely that calpain activation does not play a large role in the formation of dendritic varicosities.

This study did not establish the mechanisms of dendritic swelling after NMDA receptor activation. Rapid dendritic shape changes may not require intracellular proteolysis. For example, NMDA application triggers depolymerization of neuronal microtubules, and pretreatment with microtubule-stabilizing compounds such as taxol prevent varicosity formation (Goldberg et al., 1994). These observations suggest a mechanism for dendritic varicosities involving calpain-independent disruption of the neuronal cytoskeleton.

Our second observation is that calpain inhibitors impeded spontaneous reversal of dendritic injury after NMDA exposure. Although the available inhibitors are not fully selective for calpain, there is evidence that calpain was specifically responsible for the observed effects on dendritic recovery. First, several structurally disparate calpain inhibitors yielded similar results. Leupeptin and calpain inhibitors I and II are relatively less specific, showing strong inhibition of cathepsins B and L, trypsin, and plasmin as well as calpain (Sasaki et al., 1990; Mehdi, 1991). Of the enzyme inhibitors used in this study, MDL28,170 demonstrates improved selectivity for calpain, although it too has approximately similar $K_{\mathrm{i}}$ values for calpain I (10 nM) and the lysosomal protease cathepsin B (25 nM) (Mehdi, 1991). The activity of cathepsin B is optimal at such acidic $\mathrm{pH}$ that it is unlikely to play a major role in our model. Second, a calpain-specific spectrin breakdown product appeared during the recovery period, but not during the immediate period of NMDA-mediated dendritic injury. The appearance of Ab38 immunoreactivity closely paralleled the process of dendritic recovery in several respects: (1) Ab38 reactivity occurred in a delayed time course (30-90 min) after NMDA application, (2) it appeared in a segmental pattern in dendrites (Fig. $7 E-F$ ), and (3) it was blocked by application of a calpain inhibitor (MDL28,170), which also blocked dendritic recovery (Fig. 7G). Together, these observations support the hypothesis that activation of intracellular calpain has a major role in remodeling neuronal structure after NMDA-induced focal dendritic injury.

\section{How does calpain contribute to dendritic remodeling?}

Calpain is unique in its capacity to cleave a large number of substrates involved in cellular physiology, including cell-surface 

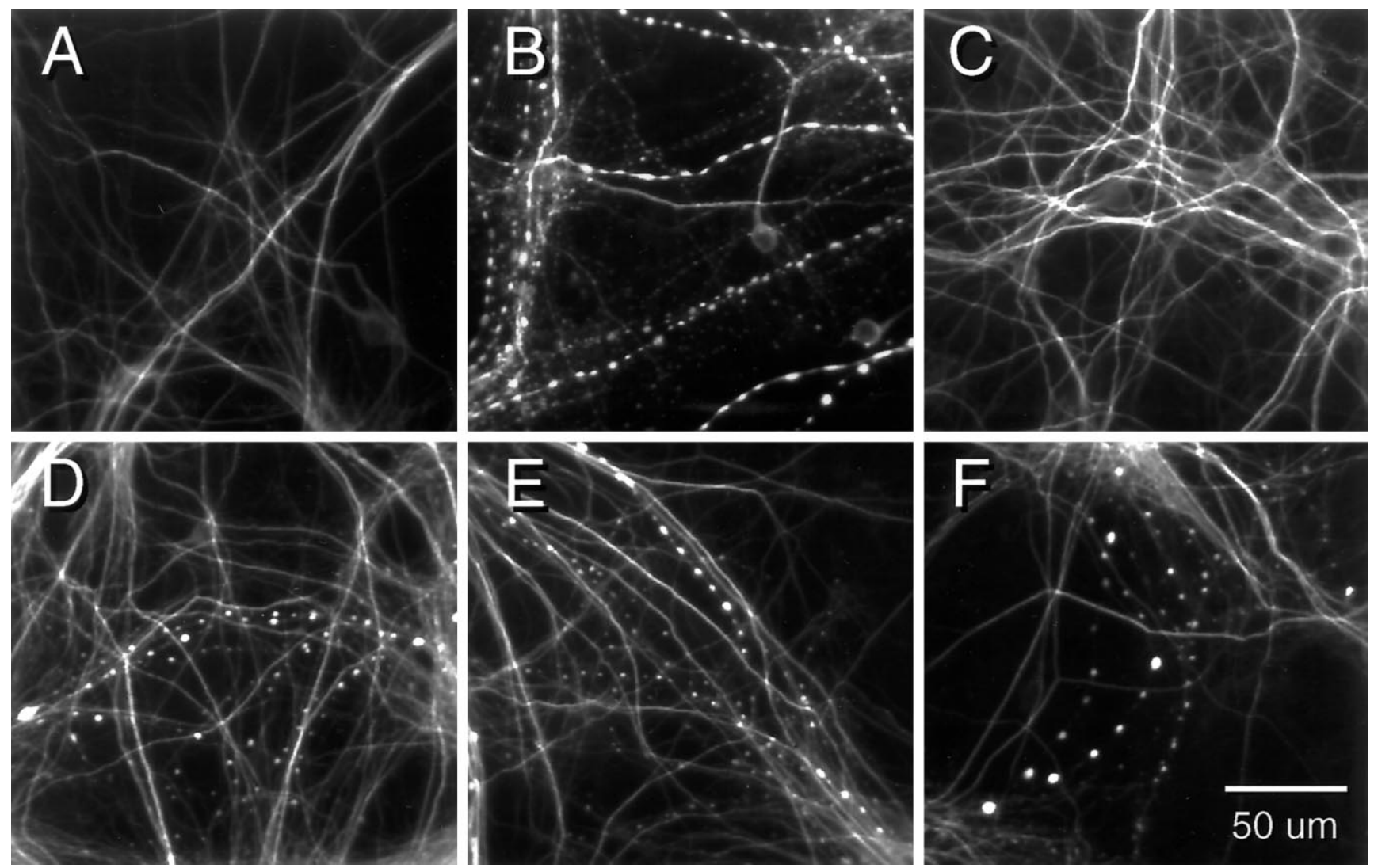

Figure 6. Several calpain inhibitors effectively block varicosity recovery. Sister cultures were exposed to wash conditions $(A), 30 \mu \mathrm{m}$ NMDA for 10 min $(B)$, or NMDA, followed by 90 min recovery $(C)$. Other sister cultures were exposed to NMDA and then washed into medium containing various calpain inhibitors, including MDL28,170 $(D)$, calpain inhibitor I $(E)$, or leupeptin $(F)$ for $90 \mathrm{~min}$. All inhibitors were present at a final concentration of $10 \mu \mathrm{m}$. MAP2 immunofluorescence shows that all inhibitors attenuated recovery of dendritic shape, as compared with untreated cultures $(C)$. Scale bar, $50 \mu \mathrm{m}$.

ion channels and receptors and intracellular mediators, including kinases, phosphatases, and transcription factors (see Saido et al., 1994). Among the most frequently considered targets of calpain degradation in neuronal injury are cytoskeletal proteins, suggesting that calpain contributes to dendritic shape changes by a process of cytoskeletal remodeling or disassembly. Although calcium-dependent cytoskeletal degradation frequently is considered detrimental to neurons, it also has been proposed as a mechanism leading to synaptic plasticity (Lynch and Baudry, 1984) and may contribute to membrane resealing after neurite transection (Schlaepfer and Bunge, 1973; Xie and Barrett, 1991). Calpain-mediated proteolysis might serve to remove aberrant cytoskeletal elements before structural repair.

The actin-binding protein brain spectrin, or fodrin, is a wellestablished cytoskeletal target for calpain proteolysis (Siman et al., 1984). Spectrin is a prominent component of the postsynaptic dendritic membrane (Ivy et al., 1988) that serves to anchor the cytoskeleton to integral cell membrane proteins. Extensive early observations by Siman, Baudry, Lynch, and coworkers established that glutamate receptor stimulation causes calpain activation and spectrin cleavage (Seubert et al., 1988; Siman and Noszek, 1988), leading to the proposal that calpain-mediated spectrin proteolysis might underlie structural changes leading to synaptic plasticity and long-term potentiation (Lynch and Baudry, 1984). Given the appearance of spectrin breakdown products in neurites during the time of dendritic remodeling, it is possible that a similar process occurs in our experiments. However, spectrin is only one of many cytoskeletal targets for calpain-mediated proteolysis. Other potential substrates include actin-binding proteins (such as $\alpha$-actinin and talin), MAP2, tubulin, tau, and neurofilaments (see Goll et al., 1992; Saido et al., 1994). Therefore, the appearance of spectrin breakdown fragments should be viewed as a marker of calpain activity, rather than as a necessary component of dendritic remodeling. Calpain activity also can result in limited proteolysis of several noncytoskeletal proteins, including membrane proteins such as voltage-gated calcium channels (Hell et al., 1996), protein kinases such as protein kinase $\mathrm{C}$ and calcium-calmodulindependent kinase II (Kwiatkowski and King, 1989; Saido et al., 1994), and protein phosphatases, including calcineurin (Saido et al., 1994); calpain might mediate varicosity recovery via any of these substrates.

Calpain activation was first evident at $30 \mathrm{~min}$ after NMDA administration and is therefore a relatively late occurrence in these experiments. MAP2 or spectrin proteolysis is not required for varicosity formation, which can be observed as early as 3-5 min after NMDA application. The time course of calpain activation in our cell culture model may be slower than that sometimes observed during hypoxic-ischemic (Saido et al., 1993; Matesic and Lin, 1994; Roberts-Lewis et al., 1994; Blomgren et al., 1995) or traumatic (Taft et al., 1992; Kampfl et al., 1996) brain injury in vivo. It is possible that calpain expression in our embryonic cortical culture system differs from that of the adult rodent brain. Although the presence of calpain I and II isoforms in cortical cultures was established by immunocytochemistry (Fig. 2) and 

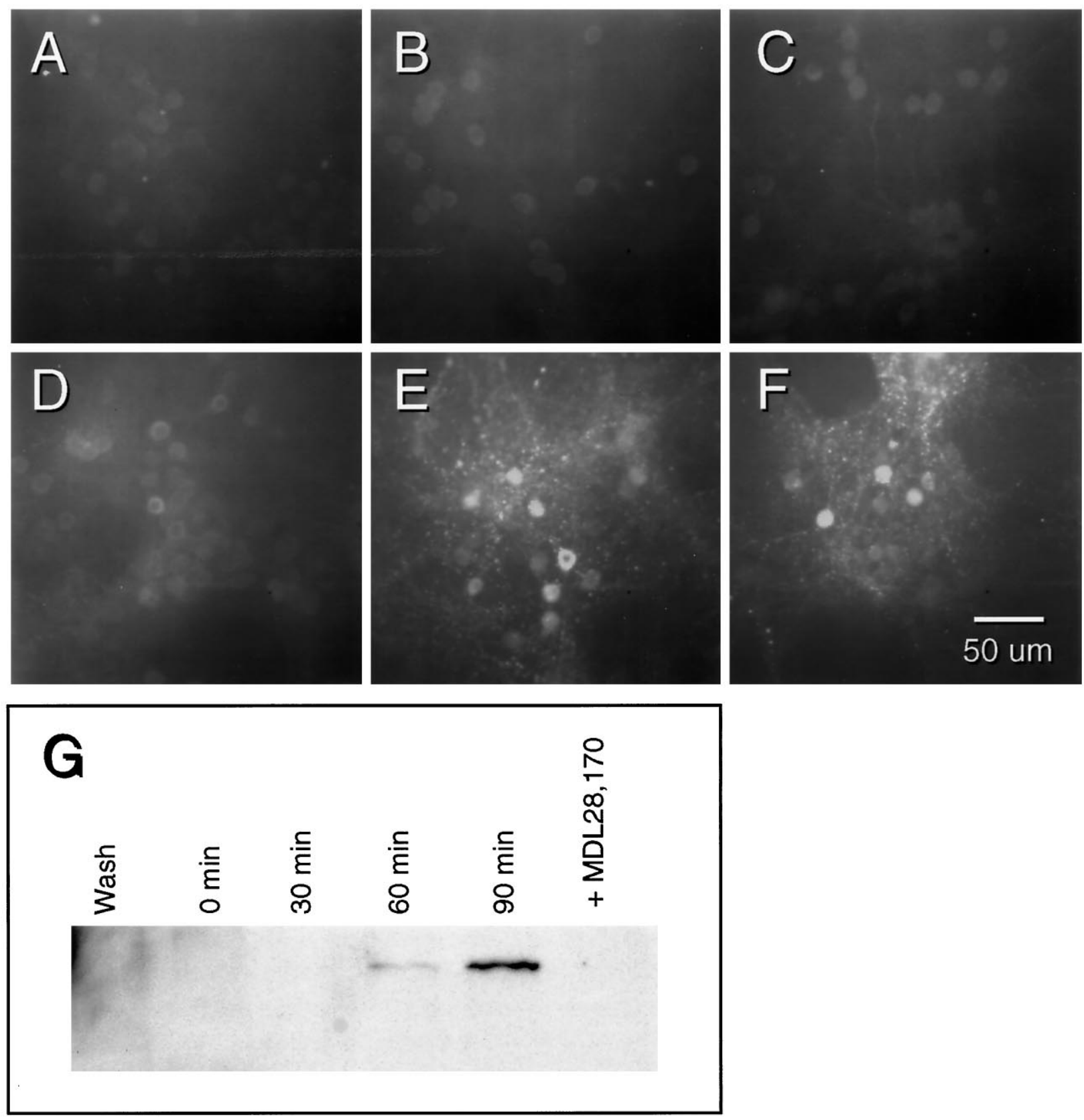

Figure 7. Calpain-specific spectrin breakdown during recovery. Sister cultures were exposed to wash conditions $(A)$ or to $30 \mu \mathrm{m}$ of NMDA for 10 min, followed by recovery periods of $0(B), 30(C), 60(D), 90(E)$, and $120(F)$ min. Immunofluorescence of the calpain-specific spectrin breakdown product $\mathrm{Ab} 38$ is readily detected at 90 and $120 \mathrm{~min}$ but is not appreciable at time points earlier than $60 \mathrm{~min}$. In similar experiments, immunoblot analysis $(G)$ using the same antibody demonstrates a similar time course of spectrin breakdown. Spectrin breakdown product was not detected in sister cultures treated with the calpain inhibitor MDL28,170 $(100 \mu \mathrm{m})$ for 90 min after NMDA exposure. Scale bar, $50 \mu \mathrm{m}$.

cytoskeletal proteolysis was profound once initiated (Meschia et al., 1995), we cannot exclude the possibility that the remodeling role of calpain is more robust in embryonic than in adult tissue. Another explanation is that the present experiments used a low NMDA concentration $(30 \mu \mathrm{M})$, which produces a low-grade insult and slower onset of calpain activation. Alternatively, calpain activation may depend on a delayed change in the balance of intracellular substances known to alter the threshold for calpain autolysis, including the endogenous inhibitor calpastatin, or positive modulators such as phospholipids (Goll et al., 1992; Saido et al., 1994).

\section{Significance of calpain-mediated dendritic remodeling}

Our studies demonstrate that calpain activation in cultured neurons does not contribute significantly to rapid development of dendritic injury after sublethal glutamate receptor activation but plays a critical role in subsequent restoration of dendritic structure. In impeding dendritic recovery, calpain inhibitors might have lasting effects on the function of neurons that survive excitotoxic insults. These results do not conflict with studies demonstrating a protective action of calpain inhibitors in the setting of lethal neuronal injury from cerebral ischemia or trauma. However, they 
suggest that it may be wise to consider beneficial as well as detrimental effects of calpain activation in neuronal injury. It will be interesting to explore possible roles of calpain in nervous system development and aging, other settings in which dendritic remodeling shapes neuronal function.

\section{REFERENCES}

Bartus RT, Hayward NJ, Elliott PJ, Sawyer SD, Baker KL, Dean RL, Akiyama A, Straub JA, Harbeson SL, Li Z, Powers J (1994) Calpain inhibitor AK295 protects neurons from focal brain ischemia. Effects of postocclusion intra-arterial administration. Stroke 25:2265-2270.

Bartus RT, Elliott PJ, Hayward NJ, Dean RL, Harbeson S, Straub JA, Li Z, Powers JC (1995) Calpain as a novel target for treating acute neurodegenerative disorders. Neurol Res 17:249-258.

Bateman MC, Goldberg MP (1992) Altered dendritic morphology in diI-labeled cortical neurons deprived of oxygen and glucose in vitro. Soc Neurosci Abstr 18:1583.

Bindokas VP, Miller RJ (1995) Excitotoxic degeneration is initiated at nonrandom sites in cultured rat cerebellar neurons. J Neurosci 15:6999-7011.

Blomgren K, Kawashima S, Saido TC, Karlsson JO, Elmered A, Hagberg H (1995) Fodrin degradation and subcellular distribution of calpains after neonatal rat cerebral hypoxic-ischemia. Brain Res 684:143-149.

Brorson JR, Marcuccilli CJ, Miller RJ (1995) Delayed antagonism of calpain reduces excitotoxicity in cultured neurons. Stroke 26:1259-1266.

Caner H, Collins JL, Harris SM, Kassell NF, Lee KS (1993) Attenuation of AMPA-induced neurotoxicity by a calpain inhibitor. Brain Res 607:354-356.

Chard PS, Bleakman D, Savidge JR, Miller RJ (1995) Capsaicin-induced neurotoxicity in cultured dorsal root ganglion neurons: involvement of calcium-activated proteases. Neuroscience 65:1099-1108.

Di Stasi AM, Gallo V, Ceccarini M, Petrucci TC (1991) Neuronal fodrin proteolysis occurs independently of excitatory amino acid-induced neurotoxicity. Neuron 6:445-454.

Elliget KA, Phelps PC, Trump BF (1994) Cytosolic $\mathrm{Ca}^{2+}$ elevation and calpain inhibitors in $\mathrm{HgCl}_{2}$ injury to rat kidney proximal tubule epithelial cells. Pathobiology 62:298-310.

Emery DG, Lucas JH (1995) Ultrastructural damage and neuritic beading in cold-stressed spinal neurons with comparisons to NMDA and A23187 toxicity. Brain Res 692:161-173.

Faddis BT, Goldberg MP (1995) Role of calpain in development and recovery of excitotoxic dendritic injury in vitro. Soc Neurosci Abstr 21:608.

Goldberg MP, Freeman JK, Rosengarten AM (1994) Sublethal NMDA receptor activation rapidly disrupts microtubules in cultured neurons. Soc Neurosci Abstr 20:1529.

Goll DE, Thompson VF, Taylor RG, Zalewska T (1992) Is calpain activity regulated by membranes and autolysis or by calcium and calpastatin? Bioessays 14:549-556.

Hell JW, Westenbroek RE, Breeze LJ, Wang KKW, Chavkin C, Catterall WA (1996) $N$-Methyl-D-aspartate receptor-induced proteolytic conversion of postsynaptic class C L-type calcium channels in hippocampal neurons. Proc Natl Acad Sci USA 93:3362-3367.

Honig MG, Hume RI (1986) Fluorescent carbocyanine dyes allow living neurons of identified origin to be studied in long-term cultures. J Cell Biol 103:171-187.

Hori N, Carpenter DO (1994) Functional and morphological changes induced by transient in vivo ischemia. Exp Neurol 129:279-289.

Hsu M, Buzsaki G (1993) Vulnerability of mossy fiber targets in the rat hippocampus to forebrain ischemia. J Neurosci 13:3964-3979.

Hyrc KH, Handran SD, Rothman SM, Goldberg MP (1996) Low-affinity calcium indicators distinguish lethal calcium entry during glutamate receptor activation in cultured neurons. Soc Neurosci Abstr 22:798.

Ivy G, Seubert P, Baudry M, Lynch G (1988) Presence of brain spectrin in dendrites of mammalian brain: technical factors involved in immunocytochemical detection. Synapse 2:329-333.

Kampfl A, Zhao X, Whitson JS, Posmantur R, Dixon CE, Yang K, Clifton GL, Hayes RL (1996) Calpain inhibitors protect against depolarizationinduced neurofilament protein loss of septo-hippocampal neurons in culture. Eur J Neurosci 8:344-352.

Koh JY, Choi DW (1987) Quantitative determination of glutamatemediated cortical neuronal injury in cell culture by lactate dehydrogenase efflux assay. J Neurosci Methods 20:83-90.
Kwei S, Jiang C, Haddad GG (1993) Acute anoxia-induced alterations in MAP2 immunoreactivity and neuronal morphology in rat hippocampus. Brain Res 620:203-210.

Kwiatkowski AP, King MM (1989) Autophosphorylation of the type II calmodulin-dependent protein kinase is essential for formation of a proteolytic fragment with catalytic activity. Implications for long-term synaptic potentiation. Biochemistry 28:5380-5385.

Lee KS, Frank S, Vanderklish P, Arai A, Lynch G (1991) Inhibition of proteolysis protects hippocampal neurons from ischemia. Proc Natl Acad Sci USA 88:7233-7237.

Linnik MD (1996) Role of apoptosis in acute neurodegenerative disorders. Restor Neurol Neurosci 9:219-225.

Lynch G, Baudry M (1984) The biochemistry of memory: a new and specific hypothesis. Science 224:1057-1063.

MacDermott AB, Mayer ML, Westbrook GL, Smith SJ, Barker JL (1986) NMDA-receptor activation increases cytoplasmic calcium concentration in cultured spinal cord neurones. Nature 321:519-522.

Manev H, Favaron M, Siman R, Guidotti A, Costa E (1991) Glutamate neurotoxicity is independent of calpain I inhibition in primary cultures of cerebellar granule cells. J Neurochem 57:1288-1295.

Matesic DF, Lin RC (1994) Microtubule-associated protein 2 as an early indicator of ischemia-induced neurodegeneration in the gerbil forebrain. J Neurochem 63:1012-1020.

Mehdi S (1991) Cell-penetrating inhibitors of calpain. Trends Biochem Sci 16:150-153.

Meschia JF, Faddis BT, Goldberg MP (1995) NMDA induces calpainmediated proteolysis of microtubule-associated protein and spectrin in cultured neurons. Soc Neurosci Abstr 21:608.

Miyoshi H, Umeshita K, Sakon M, Imajohohmi S, Fujitani K, Gotoh M, Oiki E, Kambayashi J, Monden M (1996) Calpain activation in plasma membrane bleb formation during tert-butyl hydroperoxide-induced rat hepatocyte injury. Gastroenterology 110:1897-1904.

Olney JW (1971) Glutamate-induced neuronal necrosis in the infant mouse hypothalamus. An electron microscopic study. J Neuropathol Exp Neurol 30:75-90.

Park JS, Bateman MC, Goldberg MP (1996) Rapid alterations in dendrite morphology during sublethal hypoxia or glutamate receptor activation. Neurobiol Dis 3:215-227.

Perlmutter LS, Siman R, Gall C, Seubert P, Baudry M, Lynch G (1988) The ultrastructural localization of calcium-activated protease "calpain" in rat brain. Synapse 2:79-88.

Petrozzino JJ, Pozzo Miller LD, Connor JA (1995) Micromolar $\mathrm{Ca}^{2+}$ transients in dendritic spines of hippocampal pyramidal neurons in brain slice. Neuron 14:1223-1231.

Rajdev S, Reynolds IJ (1993) Calcium green-5N, a novel fluorescent probe for monitoring high intracellular free $\mathrm{Ca}^{2+}$ concentrations associated with glutamate excitotoxicity in cultured rat brain neurons. Neurosci Lett 162:149-152.

Rami A, Krieglstein J (1993) Protective effects of calpain inhibitors against neuronal damage caused by cytotoxic hypoxia in vitro and ischemia in vivo. Brain Res 609:67-70.

Ramon y Cajal S (1909) Histologie du systeme nerveux de l'homme et des vertebres. Paris: Maloine.

Ramon y Cajal S (1995) Histology of the nervous system (Swanson N, Swanson LW, trans). Oxford: Oxford UP.

Roberts-Lewis JM, Savage MJ, Marcy VR, Pinsker LR, Siman R (1994) Immunolocalization of calpain I-mediated spectrin degradation to vulnerable neurons in the ischemic gerbil brain. J Neurosci 14:3934-3944.

Rose K, Goldberg MP, Choi DW (1993) Cytotoxicity in murine cortical cell culture. In: In vitro biological methods. Methods in toxicology. (Tyson CA, Frazier JM, eds), pp 46-60. San Diego: Academic.

Saatman KE, Murai H, Bartus RT, Smith DH, Hayward NJ, Perri BR, McIntosh TK (1996) Calpain inhibitor ak295 attenuates motor and cognitive deficits following experimental brain injury in the rat. Proc Natl Acad Sci USA 93:3428-3433.

Saido TC, Yokota M, Nagao S, Yamaura I, Tani E, Tsuchiya T, Suzuki K, Kawashima S (1993) Spatial resolution of fodrin proteolysis in postischemic brain. J Biol Chem 268:25239-25243.

Saido TC, Sorimachi H, Suzuki K (1994) Calpain: new perspectives in molecular diversity and physiological-pathological involvement. FASEB J 8:814-822.

Sasaki T, Kishi M, Saito M, Tanaka T, Higuchi N, Kominami E, Katunuma N, Murachi T (1990) Inhibitory effect of di- and tripeptidyl aldehydes on calpains and cathepsins. J Enzym Inhib 3:195-201. 
Schlaepfer WW, Bunge RP (1973) Effects of calcium ion concentration on the degeneration of amputated axons in tissue culture. J Cell Biol 59:456-470.

Seubert P, Larson J, Oliver M, Jung MW, Baudry M, Lynch G (1988) Stimulation of NMDA receptors induces proteolysis of spectrin in hippocampus. Brain Res 460:189-194.

Siman R (1992) Proteolytic mechanism for the neurodegeneration of Alzheimer's disease: review. Ann NY Acad Sci 674:193-202.

Siman R, Noszek JC (1988) Excitatory amino acids activate calpain I and induce structural protein breakdown in vivo. Neuron 1:279-287.

Siman R, Baudry M, Lynch G (1984) Brain fodrin: substrate for calpain I, an endogenous calcium-activated protease. Proc Natl Acad Sci USA 81:3572-3576.

Stewart GR, Olney JW, Pathikonda M, Snider WD (1991) Excitotoxicity in the embryonic chick spinal cord. Ann Neurol 30:758-766.
Taft WC, Yang K, Dixon CE, Hayes RL (1992) Microtubule-associated protein 2 levels decrease in hippocampus following traumatic brain injury. J Neurotrauma 9:281-290.

Wang KK, Yuen PW (1994) Calpain inhibition: an overview of its therapeutic potential, a review. Trends Pharmacol Sci 15:412-419.

Wang KKW, Nath R, Posner A, Raser KJ, Burokerkilgore M, Hajimohammadreza I, Probert AW, Marcoux FW, Ye QH, Takano E, Hatanaka M, Maki M, Caner H, Collins JL, Fergus A, Lee KS, Lunney EA, Hays SJ, Yuen PW (1996) An alpha-mercaptoacrylic acid derivative is a selective nonpeptide cell-permeable calpain inhibitor and is neuroprotective. Proc Natl Acad Sci USA 93:6687-6692.

Xie XY, Barrett JN (1991) Membrane resealing in cultured rat septal neurons after neurite transection: evidence for enhancement by $\mathrm{Ca}^{2+}$ triggered protease activity and cytoskeletal disassembly. J Neurosci 10:3257-3267. 